\section{Review of obstetric fistulas in a rural hospital in South-South Nigeria}

\author{
Aniefiok J. Umoiyoho, ${ }^{1}$ \\ Aniekan M. Abasiattai, ${ }^{1}$ Okon A. Akaiso² \\ 'Department of Obstetrics/Gynaecology, \\ University of Uyo Teaching Hospital, Uyo; \\ ${ }^{2}$ Department of Surgery, University of \\ Uyo Teaching Hospital, Uyo, Nigeria
}

\section{Abstract}

Background. Obstetric fistula is a devastating medical condition associated with adverse social, psychological and reproductive health consequences. This study was carried out to review the pattern of presentation and outcome of patients with obstetric fistulas in a rural health facility in South-South Nigeria.

Materials and Method. A retrospective review of case notes of 51 patients with obstetric fistula that were managed at the Family Life Center, Mbribit Itam, in Itu, Local Government Area of Akwa Ibom State.

Results. During the study period, 51 obstetric fistulas were repaired in the hospital. The ages of the patients ranged from 15 to 50 years with median age of 25.8 years and modal age group of 21-30 years (45.1\%). The majority of the patients were of low parity (72.5\%), 56.9\% had no formal education and $27.5 \%$ were traders. Thirty four patients (66.7\%) had their fistulas for between 1 and 6 years, 19.6\% of the patients had juxta-cervical fistulas, while eight (15.7\%) had circumferential loss of the urethra. Thirty-seven (72.5\%) of them where unbooked and thus had no antenatal care, while 4 (7.8\%) booked and had antenatal care in conventional health facilities. Thirty-four patients $(66.7 \%)$ remained dry twenty-one days after surgery, thirteen (23.5\%) were still wet, while 4 patients (7.8\%) had stress incontinence despite repair.

Conclusion. Obstetric fistulas are found most commonly among young, poorly educated women of low parity who do not avail themselves of orthodox ANC in our environment. Government, community and religious leaders must make concerted efforts to ensure women obtain formal education and when pregnant, have access to emergency obstetric care even if resident in the rural areas. Government, relevant non-Governmental organisations, community leaders and health workers should through relevant health messages enlighten women in the community about obstetric fistulas and the dangers of delivering in unorthodox health facilities. More medical personnel should be trained as the first attempt at repair is the one that is most likely to succeed.

\section{Introduction}

An obstetric fistula is an abnormal opening between the lower urinary tract and genital tract or between the rectum and vagina which results in continuous dribbling of urine, faeces or both and virtually follows neglected or prolonged obstructed labour. ${ }^{1}$ It is a devastating medical condition which is associated with adverse social, psychological and reproductive health consequences. Due to access to excellent emergency obstetric care, obstetric fistulas have virtually been eradicated from the industrialized countries, and if they occur at all are usually injuries that are sustained during surgery, which are repaired without delay. ${ }^{2,3}$ However, poverty, scarcity of health facilities, lack of good quality emergency obstetric care services, ignorance, adverse religious beliefs and cultural practices are responsible for the high prevalence of obstetric fistulas in Sub-Saharan Africa. ${ }^{2}$

Though the actual prevalence of fistulas is not known, the World Health Organisation (WHO) estimates that over 2 million women are still living with untreated fistulas while 50,000 to 100,000 develop fistulas annually. ${ }^{4}$ In West Africa, 3 to 4 out of every 1000 deliveries results in obstetric fistula and in Nigeria where the prevalence of obstetric fistulas is one of the highest in the world, about 800,000 women are currently reported to be living with fistulas with as many as 20,000 being afflicted each year. ${ }^{5}$ In northern Nigeria, where some of the largest number of cases have been reported in literature, there are currently an estimated 150,000 unrepaired cases of fistulas. ${ }^{6}$

Obstetric fistulae are always accompanied with social and cultural stigma, along with the persistent offensive odour of urine and discomfort due to continuous leakage of urine from the vagina with excoriation of the adjacent genital areas and the painful rashes these produces. ${ }^{7}$ The victims are often rejected by their husbands, ostracized by their families and communities, and hence suffer severe psychological damage and are often forced to live as destitutes. ${ }^{1,7}$

Despite its high prevalence, there are few studies on obstetric fistulas in Nigeria and most of them were conducted in tertiary health centers in the Northern part of the country. Data from the southern part of Nigeria are scare and to the best of the knowledge of the authors, none has been published from a secondary health facility.

The Family Life Center, Mbribit Itam, is located in Itu Local Government Area of Akwa Ibom State in the south-south geopolitical zone of Nigeria. It was founded in 1990 by the Medical Missionaries of Mary and is primarily dedicated to the repair of obstetric fistulas. It has 45 beds and approximately 100-150 fistula
Correspondence: Dr. Aniekan M. Abasiattai, Department of Obstetrics/Gynaecology, University of Uyo Teaching Hospital, PMB 1136, Uyo, Akwa Ibom State, Nigeria.

Tel: +234.8023174734 .

E-mail: animan74@yahoo.com

Key words: obstetric fistula, rural hospital, southern Nigeria, urinary incontinence.

Acknowledgements: the authors are very grateful to the staff of the Family Life Center, Mbribit Itam, for permitting to carry out this study.

Received for publication: 24 April 2011.

Accepted for publication: 11 0ctober 2011.

This work is licensed under a Creative Commons Attribution NonCommercial 3.0 License (CC BYNC 3.0).

(C) Copyright A.J. Umoiyoho et al., 2011

Licensee PAGEPress, Italy

Urogynaecologia 2011; 25:e7

doi:10.4081/uij.2011.e7

surgeries are performed annually. Once a year, a specialist fistula surgeon visits the hospital to perform fistula surgeries for a period of about a month. This preliminary prospective study was conducted at the center; a rural health facility with the aim of reviewing the pattern of presentation and outcome of patients with obstetric fistulas that were repaired in the hospital.

\section{Materials and Methods}

Every year, cases of vesico-vaginal fistula that fail following primary repair and those deemed to be complex (over a twelve month period) are reserved for the visiting fistula surgeon. Fifty-one consecutive patients who had obstetric fistulas and underwent repair between $1^{\text {st }}$ and $28^{\text {th }}$ February 2009 were retrospectively studied. Data collected included socio-demographic characteristics of the patients, place of delivery, duration of fistula, number of attempts at repair, state of residence, anatomical type and outcome of repair. The classification of fistulas used in this study is that proposed by Lawson. ${ }^{8}$

\section{Results}

During the study period, 51 obstetric fistulas (which all followed prolonged obstructed labour) were repaired in the hospital. The ages of the patients ranged from 15 to 50 years with median age of 25.8 years and modal age group 
of 21-30 years (45.1\%). Majority of the patients were of low parity (paral-2- 72.5\%), 56.9\% had no formal education and $27.5 \%$ were traders (Table 1).

Twelve patients (23.5\%) had had their fistulas for less than a year while 34 patients (66.7\%) had their fistulas for between 1 and 6 years. Fifteen $(29.4 \%)$ of the patients had large fistulas, eight (15.7\%) of the patients had circumferential loss of the urethra while $1(2.0 \%)$ had complete urethral loss (Table 2). Fortyfour patients (86.3\%) had previous attempts at repair. Twenty eight (54.9\%) patients had had their fistulas repaired once, seven patients (13.7\%) had had their fistulas repaired four times, 5 (9.8\%) had had theirs repaired thrice, three patients $(5.9 \%)$ had undergone repair twice while one had had hers repaired nine times. Thirty-seven (72.5\%) of them where unbooked and thus had no antenatal care, 10 (19.6\%) were antenatal clinic defaulters, while 4 (7.8\%) booked and had antenatal care in conventional health facilities. Fifteen patients (29.4\%) came from neighbouring states, 8 (15.7\%) patients came from South-Eastern Nigeria and 2 (3.9\%) travelled from South Western Nigeria. All the fistulas were repaired through the vagina. Duration of surgery ranged between $30 \mathrm{~min}$ and $3 \mathrm{~h}$. Three patients (5.9\%) had postoperative febrile morbidity while two patients (3.9\%) had urethral catheter blockage which were successfully flushed. Blood loss ranged between 100-300 $\mathrm{mL}$. Thirty-four patients (66.7\%) remained dry twenty-one days after surgery, thirteen (23.5\%) were still wet, while 4 patients (7.8\%) had stress incontinence despite repair.

\section{Discussion}

Obstetric fistula is considered to be one of the most dehumanising conditions that affect women. As shown in this study and documented by several other authors, ${ }^{2,3,9,10}$ over $90 \%$ of genital tract fistulas follow prolonged obstructed labour. Prolonged impaction of the foetal presenting part results in ischaemic necrosis of the intervening anterior vaginal and bladder walls and the posterior vaginal wall and rectum with resultant sloughing of these soft tissues and the formation of vesicovaginal and rectovaginal fistulas. ${ }^{11}$

Majority of the patients were in their twenties which represents the peak period of their reproductive life. This is similar to what occurs in other sub-Saharan countries, ${ }^{12,13}$ but is in contrast to what obtains in the northern part of Nigeria ${ }^{6,9,10}$ where teenage pregnancy following early marriage is culturally acceptable and still very much practiced. Hence, in these areas, girl-children begin childbearing before pelvic growth is complete leading to a very high prevalence of obstetric fistula.

Majority of the patients were of low parity. This is what obtains in most other studies. ${ }^{2,7,9,10,14}$ The poor socio-economic background of the patients is also reflected in this study by their low educational level and their poor health seeking behaviour typified by poor utilization of orthodox health care facilities for antenatal care (ANC) and delivery. Only 5.9\% of the patients had secondary level education while $72.5 \%$ of the patients did not receive formal ANC and attempted to deliver in unconventional health facilities where they were kept for several days with obstructed labour. They subsequently developed fistulas after the obstruction was relieved in hospital where they were taken as a last resort. This is also the observation by most other Nigerian authors and indeed authors from other countries in sub-Saharan Africa., ${ }^{2,13}$ In Nigeria, only $35.0 \%$ of women are reported to deliver in health institutions (2008 Nigeria Demographic and Health Survey) and majority of pregnant women in south-south Nigeria still prefer to obtain ANC and deliver in unorthodox health facilities. ${ }^{16,17}$

In this study, more than $76 \%$ of the patients had been living with their fistulas for over one year, and $9.8 \%$ had been living with theirs for over six years. This is similar to a study in Niger Republic ${ }^{13}$ where $71 \%$ of the patients with vesicovaginal fistulas presented for treatment after one year. This further highlights the plight of women with fistulas in our environment and the suffering they undergo. A combination of factors including inadequate information about fistula repair, traditional restrictions on women, cultural taboos, illiteracy, scarcity of health centers and competent staff have been documented to hinder women with fistulas from seeking appropriate health care. ${ }^{11}$

Almost half of the patients came from other states, $29.4 \%$ of them came from neighbouring states while $19.6 \%$ came from other distant states. These highlights the suffering women with fistulas undergo in order to access care. A similar study conducted in Kano, Nigeria ${ }^{10}$ showed that $82.7 \%$ of their patients had to travel long distances by lorries, vans or donkeys inorder to access repair after residing for several weeks in waiting homes. In addition over $50 \%$ of them had to travel various distances on foot to market places/stations where they could board the lorries or vans.

A success rate of $66.7 \%$ was recorded in this study. Available evidence indicates that according to the severity of the injury, between 60 and $98 \%$ of fistulas are repaired successfully. ${ }^{11}$ Success rates of $75.0 \%, 1487.9 \%,{ }^{9}$ and $73.0 \%{ }^{12}$ have been reported from other centers in Nigeria and sub-Saharan Africa. Results of fistula surgery are also influenced by the fistula site and size, degree of scarring, number of previous repair attempts, the overall health of the patient, the availability of health facilities and experience and expertise of the surgeon. The fistulas in this review were mostly complicated and complex ones which were reserved for the expert surgeon. These may explain the relatively low success rate despite the experience of the surgeon.

Though this study reviewed fistula surgeries reserved for an expert fistula surgeon and the sample size was relatively small, this is the first study from this fistula center and brings to light the burden of fistulas in our environment and what our women go through to access care.

In conclusion, obstetric fistula, a devastating obstetric complication is still prevalent in our environment. In addition, it is found most commonly among young, poorly educated

Table 1. Demographic characteristics of the patients.

\begin{tabular}{lc} 
Parameter & No. (\%) \\
Age & \\
$\leq 20$ & $15(29.4)$ \\
$21-30$ & $23(45.1)$ \\
$31-40$ & $9(17.6)$ \\
$>40$ & $1(2.0)$ \\
Unknown & $3(5.9)$ \\
Parity & \\
P 1-2 & $39(76.5)$ \\
P 3-4 & $8(15.7)$ \\
$\geq$ P 5 & $4(7.8)$ \\
\hline Occupation & \\
Trader & $14(27.5)$ \\
Student & $12(23.5)$ \\
Housewife & $11(21.6)$ \\
Famer & $6(11.8)$ \\
Caterer & $3(5.9)$ \\
Teacher & $1(2.0)$ \\
Civil servant & $1(2.0)$ \\
Preacher & $1(2.0)$ \\
Unemployed & $2(3.9)$ \\
Educational status & \\
No formal education & $29(56.9)$ \\
Primary level education & $19(37.2)$ \\
Secondary level education & $3(5.9)$ \\
\hline
\end{tabular}

Table 2. Duration and type of fistula.

\begin{tabular}{|c|c|}
\hline Parameter & No. $(\%)$ \\
\hline \multicolumn{2}{|l|}{ Duration of fistula (years) } \\
\hline$<1$ & $12(23.5)$ \\
\hline $1-3$ & $26(51.0)$ \\
\hline $4-6$ & $8(15.7)$ \\
\hline$>6$ & $5(9.8)$ \\
\hline \multicolumn{2}{|l|}{ Type of fistula } \\
\hline Large fistula & $15(29.4)$ \\
\hline Juxta-cervical & $10(19.6)$ \\
\hline Juxta-urethral & $7(13.7)$ \\
\hline Combined (VF+ RVF) & $7(13.7)$ \\
\hline Mid vaginal & $6(11.8)$ \\
\hline Vesico-cervical & $4(7.8)$ \\
\hline Urethro-vaginal & $2(3.9)$ \\
\hline
\end{tabular}

WF, vesico-vaginal fistula; RVF, recto-vaginal fistula. 
women of low parity who do not avail themselves of orthodox ANC. To stem this tide, concerted efforts must be made by Government, community and religious leaders to ensure women obtain formal education and when pregnant have access to emergency obstetric care even if resident in the rural areas.

Government, relevant non-Governmental organisations, community leaders and health workers should through relevant health messages enlighten women in the community about obstetric fistulas and the dangers of delivering in unorthodox health facilities. More medical personnel should be trained as the first attempt at repair is the one that is most likely to succeed.

\section{References}

1. Ahmed S, Holtz SA. Social and economic consequences of Obstetric fistula: life changed forever? Int $\mathrm{J}$ Gynaecol Obstet 2007;99:510-5.

2. Ekanem EI, Ekanem AD, Ekabua JE, et al. Review of Obstetric Genito-urinary fistulae in the University of Calabar Teaching Hospital, Calabar, Nigeria. Nig J Clin
Practice 2010;13;326-30.

3. Donnay F, Ramsey K. Eliminating Obstetric fistula: progress in partnership. Int J Gynaecol Obstet 2006;94:254-61.

4. De Bernis L. Obstetric fistula: Guiding principles for clinical management and programme development, a new WHO guideline. Int J Gynaecol Obstet 2007;99: S117-21.

5. Shittu OS, Ojengbede OA, Wara LHI. A review of post operative care for obstetric fistulas in Nigeria. Int $\mathbf{J}$ Gynaecol Obstet 2007;99:S79-84.

6. Hassan MA, Ekele BA. Vesicovaginal fistula: do the patients know the cause? Annals of Afr Med 2009;8:122-6.

7. Nisar N, Yousfani S, Muntaz F. Profile of women who experienced vesicovaginal fistuala due to obstetric trauma: results from survey at gynaecological camp 2005. Pak J Med Sci 2010;26:62-5.

8. Lawson JB. Birth canal injuries. Proc R Soc Med 1968;61;368-70.

9. Iyaiya MA, Aboyeji PA. Obstetric Urogenital fistula: The Ilorin experience, Nigeria. West Afr J Med 2004;23:7-9.

10. Jido TA, Sadauki HM. Aspects of social problems of vesicovaginal fistula patients in Kano. Trop J Obstet Gynaecol 2005;22:
133-5.

11. Creanga AA, Genadry RR. Obstetric fistulas: A clinical review. Int J Gynaecol Obstet 2007;99:540-6.

12. Rijken Y, Chilopora GC. Urogenital and Rectovaginal fistulas in Southern Malawi: A report on 407 patients. Int J Gynaecol Obstet 2007;99:585-9.

13. Nafiou I, Idrissa A, Ghaichaton AK, et al. Obstetric Vesicovaginal fistulas at the National Hospital of Niamey, Niger. Int $\mathbf{J}$ Gynaecol Obstet 2007;99:571-4.

14. Inimgba NM, Okpani AOU, John CT. Vesicovaginal fistulae in Port Harcourt, Nigeria. Trop J Obstet Gynaecol 1999;16: 49-51.

15. National Population Commission, ICF Macro. Nigeria Demographic and Health Survey 2008: Key finding. NPC and ICF Macro, Calverton, MD, USA, 2009.

16. Udoma EJ, Ekanem AD, Abasiattai AM, Bassey EA. Reasons for preference of delivery in Spiritual Church based clinics by women of South-South Nigeria. Nig J Clin Practice 2008;11:100-3.

17. Etuk SJ, Itam IH, Asuquo EEJ. Role of Spiritual Churches in antenatal clinic default in Calabar, Nigeria. East Afr Med J 1999;76:630-43. 